\title{
Applicant reactions to selection events: four studies into the role of attributional style and fairness perceptions
}

\section{Citation for published version (APA):}

Schinkel, S., van Vianen, A. E. M., \& Ryan, A. M. (2016). Applicant reactions to selection events: four studies into the role of attributional style and fairness perceptions. International Journal of Selection and Assessment, 24(2), 107-118. https://doi.org/10.1111/ijsa.12134

DOI:

10.1111/ijsa.12134

Document status and date:

Published: 01/06/2016

\section{Document Version:}

Publisher's PDF, also known as Version of Record (includes final page, issue and volume numbers)

\section{Please check the document version of this publication:}

- A submitted manuscript is the version of the article upon submission and before peer-review. There can be important differences between the submitted version and the official published version of record. People interested in the research are advised to contact the author for the final version of the publication, or visit the $\mathrm{DOI}$ to the publisher's website.

- The final author version and the galley proof are versions of the publication after peer review.

- The final published version features the final layout of the paper including the volume, issue and page numbers.

Link to publication

\section{General rights}

Copyright and moral rights for the publications made accessible in the public portal are retained by the authors and/or other copyright owners and it is a condition of accessing publications that users recognise and abide by the legal requirements associated with these rights.

- Users may download and print one copy of any publication from the public portal for the purpose of private study or research.

- You may not further distribute the material or use it for any profit-making activity or commercial gain

- You may freely distribute the URL identifying the publication in the public portal.

If the publication is distributed under the terms of Article 25fa of the Dutch Copyright Act, indicated by the "Taverne" license above, please follow below link for the End User Agreement:

www.tue.nl/taverne

Take down policy

If you believe that this document breaches copyright please contact us at:

openaccess@tue.nl

providing details and we will investigate your claim. 


\title{
Applicant Reactions to Selection Events: Four studies into the role of attributional style and fairness perceptions
}

\author{
Sonja Schinkel*, Annelies E. M. van Vianen** \\ and Ann Marie Ryan***
}

*Department of Human Performance Management, Technical University Eindhoven, Den Dolech 2, 5600 MB, Eindhoven, The Netherlands. sonja.schinkel@gmail.com

**Department of Work and Organizational Psychology, University of Amsterdam, The Netherlands

***Department of Industrial and Organizational Psychology, Michigan State University, MI, USA

In four studies, applicants' $(N=478)$ organizational attractiveness perceptions and recommendation intentions following selection outcomes were measured. In three field studies, actual applicants' perceptions were measured in authentic, high-stakes application contexts, both preprocedure and postoutcome. A fourth, hypothetical, study was added to increase internal validity. Consistent positive relationships between procedural fairness and reactions were found. Further, attributional style moderated the distributive fairness-attractiveness relationship in the field studies, but not in the laboratory study. In general, optimistically attributing applicants reported higher organization attraction than less optimistic individuals when the outcome was perceived as fair, but lower attraction when the outcome was perceived as unfair. For recommendation intentions, results were less consistent. Implications for future research and practice are discussed.

\section{Introduction}

$\mathrm{n}$ applying organizational justice theory to selection contexts, Gilliland (1993) proposed that applicants' cognitive, affective and behavioral reactions to selection events are - at least partly - determined by the extent to which they think these events are fair. For instance, individuals who perceive their selection outcome (hire/reject) or the procedure it was based on as unfair may report lower organizational attractiveness than those who have more positive perceptions. Indeed, a recent survey study showed that at least half of all job seekers developed a negative impression of the recruiting organization after being rejected for a job, and that one fifth ceased to purchase its products as a result (Stevens, 2010).

Importantly, job candidates come to the selection context with traits that color their interpretation of the organization's selection processes and outcomes (Derous, Born, \& De Witte, 2004). Therefore, the perceptions they have of an organization will - at least partly - be determined by their attributional style: the rather stable tendency of attributing events to certain causes (e.g., internal vs. external). That is, a candidate could attribute a rejection decision to their own lack of competence (i.e., internally), the strong competition for jobs or to discrimination (i.e., externally) (Ployhart \& Harold, 2004). Additionally, it has been found that differences exist between actual and perceived discrimination (Abu Ghazaleh, Den Hartog, \& Schinkel, 2008; Anderson, 2011), which may also be due to individual differences in attributing causes to events. However, the influence of applicant attributional style on organization perceptions and recommendation intentions is highly understudied, warranting further investigation of these constructs and their antecedents in different contexts.

The main contribution of this paper is that it examines the combined role of applicants' attributional styles and fairness perceptions in selection contexts. Further, whilst the perceived fairness of the outcome may be at least as important as the fairness of the procedure investigations of the relationship between applicants' distributive fairness perceptions and their perceptions of the recruiting 
organization are sparse. We consider both distributive and procedural fairness perceptions in examining the role of attributional style. Finally, as only about half of all applicant reactions studies have been conducted with actual applicants in authentic selection situations and lab studies can yield stronger effects than field studies (Hausknecht, Day, \& Thomas, 2004), we examine these relationships with three field studies and one lab study to best understand these relationships.

\section{Fairness and attributions in selection contexts}

Organizational justice theories focus on (a) distributive justice: the fairness of allocated organizational outcomes, and (b) procedural justice: the fairness of the procedures used to allocate these outcomes (Gilliland, 1994). Numerous studies have found positive relationships between perceived procedure fairness and attitudes toward recruiting organizations, such as organizational attractiveness and recommendation intentions (e.g., Bauer, Maertz, Dolen, \& Campion, 1998; Gilliland, 1994; Ployhart \& Ryan, 1997, 1998; Truxillo, Bauer, Campion, \& Paronto, 2002). For recommendation intentions and distributive fairness, moderate to strong relationships have been found in hypothetical (e.g., Gilliland, 1994) as well as authentic (Ployhart \& Ryan, 1997, 1998) contexts (see also: Hausknecht, et al., 2004; Uggerslev, Fassina, \& Kraichi, 2012). However, only a few studies exist of relationships between distributive fairness and organizational attractiveness, and the results of these studies vary: some found direct relationships (e.g., Gilliland, 1994; Ployhart \& Ryan, 1997, 1998; Schinkel, Van Dierendonck, Van Vianen, \& Ryan, 2011), whereas others did not (e.g., Schinkel, Van Vianen, \& Van Dierendonck, 2013; Smither, Reilly, Millsap, Pearlman, \& Stoffey, 1993). Based on the first findings and Gilliland's (1993) propositions, we hypothesize:

Hypothesis 1a: Distributive fairness will be positively related to applicants' postoutcome organizational attractiveness and recommendation intentions.

Hypothesis $1 \mathrm{~b}$ : Procedural fairness will be positively related to applicants' postoutcome organizational attractiveness and recommendation intentions.

The inconsistencies in findings of the fairness-reactions relationship may be due to differences in selection methods (e.g., interview, test) studied or differential study contexts (e.g., authentic vs. hypothetical). However, it may also be contingent on other factors, such as applicants' dispositions. Indeed, applicant reactions research has typically focused on direct relationships between selection events and perceptions, attitudes, and intentions. Yet, it is very likely that these relationships are moderated by other factors (Gilliland, 1993; Ryan \& Ployhart, 2000), such as applicant attributional processing. People engage in attributional processing in order to understand the causes of their experiences. This process has been shown to occur quickly and automatically, and is initiated if an event is important, negative or unexpected (Weiner, 1986). To most applicants, selection outcomes are highly important and for many they may also be negative and unexpected, so selection contexts will likely elicit attributional processing. In line with these suggestions, Ployhart and Harold (2004) developed the Applicant AttributionReaction Theory, proposing that applicants' perceptions and behavioral consequences are influenced by their attributions about why they were selected or rejected (e.g., lack of qualifications, biased interviewer). Other researchers have explored the role of attributions in connecting fairness and organizational perceptions (e.g., Ababneh, Hackett, \& Schat, 2014). For example, Ployhart and Ryan (1997) found that some attributions moderated the link between outcome fairness and postoffer perceptions, such as recommendation intentions.

While the studies to date have focused on specific attributions after a certain selection decision, more stable individual differences in attributional processing likely play a role in how applicants process their experiences (Abramson, Seligman, \& Teasdale, 1978). A tendency to attribute negative events (e.g., rejection) to causes that are external, unstable and specific (e.g., a distracted interviewer, a difficult job market) is considered to be an optimistic attributional style, whereas a tendency to attribute negative events to internal, stable and global causes (e.g., one's own lack of qualifications or lack of interviewing skills) reflects a pessimistic style (Forsterling, 2001). Scheier and Carver (1993) note that research on attributional style converges with broader research on optimism, indicating that optimism generally relates to better mental and physical health outcomes (see, for example, research on psychological well-being, Cheng \& Furnham, 2003; depression in pregnancy, Wagner, Berenson, Harding, \& Joiner, 1998). One preliminare study showed that attributional style indeed moderated the fairness-reactions relationship in selection (Schinkel et al., 2011).

We extend existing research by arguing that attributional style plays a role in how applicants' fairness perceptions link to their perceptions of the organization. Focusing on attributional style rather than just on specific postdecision attributions is meaningful because it recognizes that individuals come to the selection context with experiences, expectations and traits that color their interpretation of the organization's selection processes (Derous et al., 2004). It is important to understand that the interpretation of a specific selection decision will be influenced by the individual's general style of attributing events. Of particular note is the locus dimension of attributions: the degree to which the occurrence of a certain event is thought to be due to factors that are either internal or external to a person (Weiner, 1986). 
Individuals with a more optimistic attributional style may react to negative or unfair selection outcomes differently than less optimistic ones, in that they will tend to see a lack of success as having an external specific cause (i.e., this particular organization) rather than about their own general capabilities or likelihood of future success (i.e., a lack in oneself or a general inability to obtain work). Consequently, optimistically attributing people may thus have more negative perceptions of and intentions toward the organization than those who tend to think of themselves as responsible for negative events. Conversely, following a positive or fair outcome, optimistic individuals will make more positive attributions toward the organization and may report even higher attractiveness and intentions than those with a pessimistic attribution style. We therefore hypothesize:

Hypothesis 2: Attributional style will moderate the relationship between distributive fairness and postoutcome a) organizational attractiveness and b) recommendation intentions, such that applicants with a more optimistic attributional style will report stronger reactions to perceived (un)fairness than applicants with a less optimistic style.

\section{Study 1}

The goal of the first study was to confirm that perceived procedural and distributive fairness would be related to applicants' perceptions of postoutcome organizational attractiveness ( $\mathrm{H} 1 \mathrm{a}$ and $\mathrm{H} 1 \mathrm{~b})$ in an authentic selection situation.

\subsection{Method}

\subsubsection{Participants and procedure}

Participants $(N=83)$ were employed individuals applying for jobs offered by a Dutch recruitment agency. All applicants who were invited for a job interview with one of the agency's recruiters and the particular client (i.e., various organizations and selection procedures) were invited to participate in the study by an explanatory letter sent to their home address, including the T1-questionnaire (preinterview) and a stamped return envelope. The voluntary nature of participation and confidentiality were emphasized. Participants were sent the T2-questionnaire shortly after learning of their selection outcome. Generally, the (semistructured) interview was the first and only step in the selection process; in three cases a second interview was planned before a decision was made. Of the 187 respondents (202 invited; response rate 93\%) who filled out the preinterview questionnaire, 120 were male (64\%); mean age was $34(S D=6.51)$, and $96 \%$ were Dutch. All respondents were applying for mid-level or higher job positions in IT, legal, finance, and technical areas; all had finalized mid-level (vocational) or higher (college/ university) education. 87 respondents (47\%) also filled out the postoutcome questionnaire (4 could not be used due to return after project deadline (30 days after receiving decision) or too many missing answers). Of the remaining respondents, 56 were rejected, twelve were hired, eight withdrew from the procedure and seven decisions were unknown (and therefore these participants' answers could not be analyzed). No significant differences were found between T1/T2-respondents and T1-only respondents.

\subsubsection{Measures}

Answers were on 5-point Likert-scales, such that higher numbers indicate higher agreement/quantity of the attribute. Procedural fairness perceptions were measured postoutcome (T2) with 17 items from the Selection Procedural Justice Scale (Bauer et al., 2001), adapted to the interview situation, e.g., 'I was treated politely during the interview' and 'There was sufficient two-way communication during the interview'. Distributive fairness perceptions were measured postoutcome (T2) with two items (Bauer et al., 2001): 'In my opinion the selection decision was rightly made' and 'I feel the outcome of the interview was fair'. Correlation between the two items was $r=.69$. Organizational attractiveness was measured preinterview (T1) and postoutcome (T2), with four items developed by Ployhart and Ryan (1998), for example, 'I find the organization where I applied for a job attractive' (see Table 2 for reliabilities).

\subsection{Results}

None of the demographic variables (gender, age, nationality, education) related to any of the study variables; therefore, these were not included in the further analyses. Means and standard deviations of T1 and T2 organizational attractiveness in the hired and rejected conditions are shown in Table 1. In accordance with Bauer et al. (1998) and Ployhart and Ryan (1997), we controlled for initial levels of attractiveness in the regression analyses. As selection outcome did not relate to attraction (see Table 2) and to preserve power, this variable was not included in Study 1 analyses (cf. Becker, 2005).

Hypotheses $1 a$ and $1 b$ predicted that distributive and procedural fairness perceptions would be positively related to postoutcome organizational attractiveness. Regression analyses with procedural and distributive fairness as independent variables and organizational attractiveness as dependent variable (with T1-attractiveness controlled for in Step 1) were performed. Results revealed that this effect was significant for procedural fairness: $F(3,72)=10.04, p<.001$ (see Table 3 ), but not for distributive fairness. The power of this step (over and above that of the previous step) is $f^{2}=.39$, which is considered large (Cohen, 1988). That is, when applicants 
reported higher procedural fairness, they perceived the organization as more attractive: This means Hypothesis $1 b$ was supported, but Hypothesis $1 a$ was not.

\section{Study 2}

The goal of Study 2 was to examine whether the relationship between distributive fairness perceptions and organization attraction and recommendation intentions would be moderated by applicants' attributional style $(\mathrm{H} 2)$.

\subsection{Method}

\subsubsection{Participants and procedure}

Participants $(N=119)$ were graduate students applying for a three-year traineeship (e.g., in retail, finance, IT) at a large Dutch bank. The entire selection procedure com-

Table 1. Means and standard deviations of preinterview and postoutcome organizational attractiveness for hired/passed and rejected applicants for Studies 1, 2, and 3

\begin{tabular}{llrlrr}
\hline & \multicolumn{2}{c}{ Hired/Passed } & & \multicolumn{2}{c}{ Rejected } \\
\cline { 2 - 2 } \cline { 5 - 6 } & $M$ & SD & & $M$ & SD \\
\hline Study 1 & & & & \\
Organizational attractiveness & & & & \\
$\quad$ T1 & 4.15 & .74 & 3.89 & .79 \\
$\quad$ T2 & $3.86^{*}$ & 1.05 & 3.25 & .95 \\
Study 2 & & & & \\
Organizational attractiveness & & & & \\
$\quad$ T1 & 4.14 & .67 & & 4.25 & .48 \\
$\quad$ T2 & $4.43^{* * *}$ & .46 & 4.10 & .45 \\
Recommendation intention & & & & \\
$\quad$ T1 & 3.60 & .85 & 3.56 & 1.08 \\
$\quad$ T2 & $3.66^{*}$ & .89 & 3.16 & .90 \\
Study 3 & & & & \\
Organizational attractiveness & & & & \\
$\quad$ T1 & 3.86 & .49 & 3.81 & .66 \\
$\quad$ T2 & 3.96 & .59 & 3.78 & .86 \\
Recommendation intention & & & & \\
$\quad$ T1 & 3.61 & 1.04 & 3.68 & .92 \\
$\quad$ T2 & 3.65 & 1.00 & 3.35 & 1.04 \\
\hline
\end{tabular}

Notes: Study 1: $N=68$. Hired, $n=12$; Rejected, $n=56$. Study 2: $N=116$. Passed, $n=94$; Rejected, $n=22$. Study 3: $N=58$. Hired, $n=18$; Rejected, $n=40$.

Differences between conditions based on Anovas: $* p=.05$, ** $p<.05$, $* * * p<.01$. prised five rounds (résumé; ability and personality test; interview; assessment exercises; board panel interview), with applicants entering each round only if they had been successful on the previous round. Questionnaires were collected at two points in time: all applicants who applied by sending in their résumé were sent an invitation to participate in the study, including the first questionnaire (T1); they were sent a second questionnaire directly following the outcome of their résumé application (i.e., invited to next step/rejected). The voluntary nature of participation was emphasized and confidentiality of answers was guaranteed.

Of the 119 respondents (150 invited; response 79\%) who filled out both questionnaires, 66 were male $(61 \%$; four unknown); mean age was $23(S D=3.65)$, and $88 \%$ were Dutch. Three questionnaires could not be used due to unknown selection decision; of the remaining 116 applicants, 94 passed the résumé selection round, and 22 did not pass.

\subsubsection{Measures}

Distributive fairness perceptions and organizational attractiveness were identical to Study 1. Correlation between the two fairness items was $r=.59$. Attributional style was measured with four hypothetical events, adapted from Proudfoot, Corr, Guest, and Gray (2001). To be able to measure stable attributional tendencies instead of reactions to a particular event, it is essential to develop hypothetical events, preferably concerning a domain that is of interest to the population studied to increase validity (Peterson \& Villanova, 1988). Therefore, all events were related to job search activities (e.g., performance on

Table 2. Means, standard deviations, reliabilities and correlations of Study 1 variables

\begin{tabular}{lccccccc}
\hline Measures & $M$ & $S D$ & 1 & 2 & 3 & 4 & 5 \\
\hline 1. Selection outcome & - & - & - & & & & \\
2. Procedural fairness & 3.83 & .44 & .15 & $(.88)$ & $(.81)$ & $(.91)(.93)$ \\
3. Distributive fairness & 2.89 & .96 & $.31^{*}$ & $.33^{* *}$ & $-.23^{*}$ & .14 \\
4. Org attract (T1) & 3.96 & .76 & .13 & .17 & .17 & \\
5. Org attract (T2) & 3.39 & 1.00 & .11 & $.57^{* * *}$ & & \\
\hline
\end{tabular}

Notes: Reliability coefficients per measurement appear on the diagonal. Selection outcome: reject $=0$; pass $=1$.

$*_{p}<.05, * * p<.01, * * * p<.001$ (two-tailed).

Table 3. Regression of organizational attractiveness on procedural and distributive fairness, Study 1

\begin{tabular}{|c|c|c|c|c|c|c|}
\hline Organizational attractiveness & $B$ & $\beta$ & $R^{2}$ & $\Delta R^{2}$ & $F$ & $\Delta F$ \\
\hline $\begin{array}{l}\text { Step } 1 \\
\text { Organizational attractiveness T1 }\end{array}$ & .08 & .06 & .03 & - & 1.92 & - \\
\hline Step 2 & & & .30 & .27 & $10.04 * * *$ & $13.78 * * *$ \\
\hline Procedural fairness & 1.18 & $.54 * * *$ & & & & \\
\hline Distributive fairness & -.02 & -.02 & & & & \\
\hline
\end{tabular}

Notes: The reported statistics are standardized regression coefficients and are for the final equation, including all independent variables. $\mathrm{df}$ Step $1=(1,74)$; df Step $2=(3,72)$; total $d f$ all steps $=75$.

$* * * p<.001$ (two-tailed). 
selection test; being hired for a job). Participants rated the extent to which they felt an event was attributable to them, for example, 'You perform badly during a job interview' (negative items recoded), with a higher score meaning a more optimistic style (i.e., more internal/external attribution for positive/negative events, respectively). Recommendation intention was measured with one item: 'I intend to recommend the organization with which I applied for a job to other job seekers' (see Table 4 for reliabilities).

\subsection{Results}

None of the demographic variables (gender, age, nationality, application experience and hiring expectation) related to the outcome variables; therefore, these were not included in further analyses. Means and standard deviations of T1 and T2 organizational attractiveness and recommendation intentions of passed and rejected applicants are shown in Table 1. Table 4 shows correlations between the study variables (including application experience and hiring expectation). Because, in this study, selection outcome was related to organization attractiveness and intentions, we ran analyses both excluding (to preserve power) and including this variable.

For testing Hypothesis $1 a$, similar regression analyses as in Study 1 were performed. Results revealed that distributive fairness was positively related to organizational attractiveness: $F(3,36)=7.52, p<.001$ and recommendation intentions: $F(3,35)=19.21, p<.01$ (see Table 5). That is, applicants who reported higher distributive fairness perceived the organization as more attractive and were more willing to recommend it to others. Thus, Hypothesis $1 a$ was supported.

Hypothesis 2 predicted that attributional style would moderate the relationship between distributive fairness and postoutcome (a) organizational attractiveness, and (b) recommendation intentions. Specifically, we proposed that applicants with a more optimistic attributional style would report stronger reactions to perceived (un)fairness than applicants with a less optimistic style. First, moderated regression analyses with distributive fairness, attributional style (Step 2), and the two-way interaction variable (Step 3) as independent, and T2-DVs as dependent

Table 4. Means, standard deviations, reliabilities and correlations of Study 2 variables

\begin{tabular}{|c|c|c|c|c|c|c|c|c|c|}
\hline Measures & $M$ & $S D$ & 1 & 2 & 3 & 4 & 5 & 6 & 7 \\
\hline 1. Selection outcome & - & - & - & & & & & & \\
\hline 2. Distrib fairness & 3.38 & 1.05 & $.53 *$ & $(.74)$ & & & & & \\
\hline 3. Attribution style & 2.19 & .76 & $-.31 *$ & .01 & $(.79)$ & & & & \\
\hline 4. Applic experience & 1.65 & .59 & .02 & -.03 & $-.20 *$ & $(-)$ & & & \\
\hline 5. Hiring expect & 3.33 & .73 & $.23^{*}$ & $.21 *$ & $-.24 *$ & .14 & $(-)$ & & \\
\hline 6. Org attract & 4.35 & .48 & $.34^{*}$ & $.28 * *$ & -.20 & -.05 & .15 & $(.85)$ & \\
\hline 7. Recom intent & 3.48 & .95 & $.37 * *$ & $.61 * *$ & -.13 & -.04 & -.01 & $.48^{* *}$ & $(-)$ \\
\hline
\end{tabular}

Notes: Reliability coefficients per measurement appear on the diagonal. Selection outcome: reject $=0$; pass $=1$.

$* p<.05, * * p<.01$ (two-tailed).

Table 5. Regression of organizational attractiveness and recommendation intention on distributive fairness and attributional style, Study 2

\begin{tabular}{|c|c|c|c|c|c|c|}
\hline Dependent variable & $B$ & $\beta$ & $R^{2}$ & $\Delta R^{2}$ & $F$ & $\Delta F$ \\
\hline \multicolumn{7}{|l|}{ Organizational attractiveness } \\
\hline Step 1 & & & .00 & - & .03 & - \\
\hline Org attract $\mathrm{T} 1$ & -.06 & -.08 & & & & \\
\hline Step 2 & & & .39 & .39 & 7.52 & $11.26 * * *$ \\
\hline Distributive fairness & .23 & $.48 * * *$ & & & & \\
\hline Attributional style & -.11 & -.20 & & & & \\
\hline Step 3 & & & & & & \\
\hline $\begin{array}{l}\text { DF } \times \text { Attrib style } \\
\text { Recommendation intention }\end{array}$ & -.38 & $-.53^{* * *}$ & .64 & .26 & 15.74 & $25.21 * * *$ \\
\hline Step 1 & & & .52 & - & $39.44 * * *$ & - \\
\hline Recommend intent $\mathrm{T} 1$ & .59 & $.56 * * *$ & & & & \\
\hline Step 2 & & & .62 & .11 & 19.21 & $4.92 *$ \\
\hline Distributive fairness & .34 & $.32 * *$ & & & & \\
\hline Attributional style & -.10 & -.08 & & & & \\
\hline Step 3 & & & .64 & .02 & 15.33 & 2.02 \\
\hline DF $\times$ Attrib style & -.24 & -.15 & & & & \\
\hline
\end{tabular}

Notes: The reported statistics are standardized regression coefficients and are for the final equation, including all independent variables. Org attract: df Step $1=(1,38)$; df Step $2=(3,36)$; df Step $3=(4,35)$; total df all steps = 39; recommend intent: $d f$ Step $1=(1,37)$; df Step $2=(3$, $35)$; $d f$ Step $3=(4,34)$; total $d f$ all steps $=38$.

$*_{p}<.05, * * p<.01, * * * p<.001$ (two-tailed). 


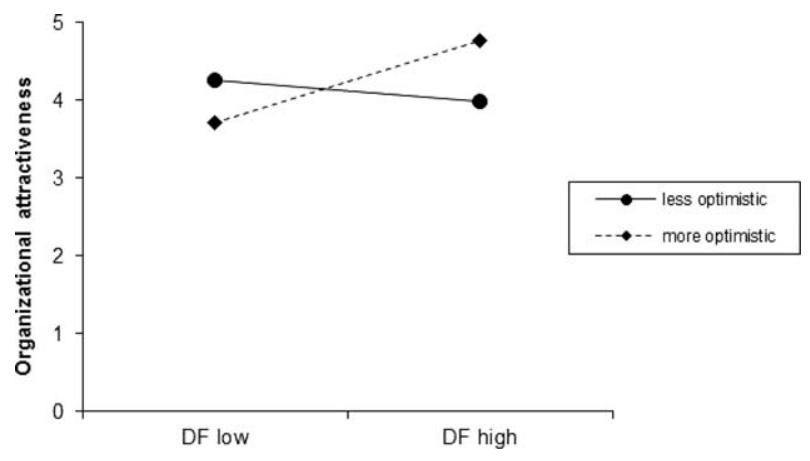

Figure 1. Organizational attractiveness across distributive fairness (DF: low vs. high) and attributional style (less vs. more optimistic), Study 2. (Figure based on $+I-1 S D$ of independent variables).

variables (with T1-DVs controlled for in Step 1) were performed. Results revealed a significant interaction effect for organization attractiveness: $F(4,35)=15.74, p<.001$, for the final equation (Table 5). Additional simple slopes analyses (Dawson, 2014) revealed that the moderation of the relationship between fairness and attractiveness was only significant at a high level $(+1 S D)$ of optimistic attribution style $(t=4.58, p<.001)$, and not at a low level. The power of this step is $f^{2}=.69$, which is considered large. Figure 1 shows that, as hypothesized, optimistically attributing applicants reacted more strongly to distributive (un)fairness in forming attractiveness perceptions. (Note that, when outcome was controlled for, this effect remained significant.)

For recommendation intentions, this effect was not found: $F(4,34)=15.33, p=n s$ (Table 5). However, this was probably due to the large drop in sample size when including $\mathrm{T} 1$ (if $\mathrm{T} 1$ included: $N=39$; if $\mathrm{T} 1$ not included: $N=116$ ): when $T 1$ was not included, a significant moderation effect was also found for recommendation intentions: $F(3,109)=8.23, R^{2}=.19 ; \beta=-.22, p<.05$, for the final equation. (Note that when outcome was also controlled for, a similarly significant result was found.) Additional slopes analyses showed that the moderation of the relationship between fairness and recommendation intention was only significant at a high level (+1 SD: $t=2.93, p<.01)$ of optimistic attribution style, and not at a low level. The pattern for recommendation intention is largely similar to that for organizational attractiveness, with optimistic applicants reporting stronger reactions to (un)fairness than less optimistic ones. This means that in this study, Hypothesis $2 a$ and $2 b$ were supported.

\section{Study 3}

The first goal of Study 3 was to replicate the Study 1 finding that procedural fairness was positively related to organizational attractiveness. Second, Study 3 sought to replicate the Study 2 finding that the relationship between distributive fairness and organization attractiveness and recommendation intentions was moderated by attributional style. As outcome did not relate to attraction, to preserve power, it was not included in Study 3 analyses (cf. Becker, 2005).

\subsection{Method}

\subsubsection{Participants and procedure}

Participants $(N=63)$ were unemployed individuals who were enrolled in a job search course, given by a large national employment agency and consisting of weekly classes with a total duration of 6 weeks. The course focused on how to write an application letter and résumé, where to search for job ads, and how to prepare for a job interview. Questionnaires were collected at two points in time. All applicants who were invited for an interview with one of the agency's clients (i.e., various organizations and selection procedures) were invited to participate in the study by an explanatory letter handed to them during the course, including the (preinterview) T1-questionnaire and a stamped return envelope. In most cases, the interview was the first and only step in the selection process; in rare cases a test or second interview was planned before a decision was made. The type and nature of the interviews (unstructured/structured) varied over the different clients. The voluntary nature of participation was emphasized and confidentiality of answers was guaranteed. Participants were given the T2-questionnaire in the class directly following their job interview (including explanation letter and return envelope). They could win a $€ 50$ gift card if they filled out both questionnaires.

Of the 78 respondents (response 95\%) on the T1questionnaire, 35 were male (46\%); mean age was 38 $(S D=9.47)$, and $93.5 \%$ were Dutch. $74 \%$ of respondents had finalized mid-level (secondary/vocational), 18\% higher education (college/university). Mean work experience in years was $14.5(S D=9.33)$. 63 respondents $(81 \%)$ also filled out the T2-questionnaire ( 5 not used due to unknown outcome). Of the remaining 58 applicants, 18 were hired and 40 rejected. No significant differences were found between T1/T2-respondents and T1-only respondents.

\subsubsection{Measures}

Measures were identical to Studies 1 and 2, with two exceptions. Procedural fairness in this study was measured with fourteen items (same as Study 1, minus three items to save space). Distributive fairness perceptions in this study were measured with one item: 'In my opinion the selection decision is rightly made' (see Table 6 for reliabilities).

\subsection{Results}

None of the demographic variables (gender, age, nationality, work experience, education) related to any of the 
Table 6. Means, standard deviations, reliabilities and correlations of Study 3 variables

\begin{tabular}{|c|c|c|c|c|c|c|c|c|c|c|}
\hline Measures & M & $S D$ & 1 & 2 & 3 & 4 & 5 & 6 & 7 & 8 \\
\hline 1. Selection outcome & - & - & - & & & & & & & \\
\hline 2. Proced fairness & 3.93 & .67 & .16 & $(.95)$ & & & & & & \\
\hline 3. Distrib fairness & 2.98 & 1.07 & .17 & $.42^{* * *}$ & $(-)$ & & & & & \\
\hline 4. Attribution style & 2.99 & .70 & -.04 & .10 & .07 & $(.80)$ & & & & \\
\hline 5. Org attract (T1) & 3.83 & .61 & .04 & $.38 * *$ & .18 & .08 & $(.84)$ & & & \\
\hline 6. Org attract (T2) & 3.85 & .77 & .10 & $.57 * * *$ & $.39 * *$ & .11 & .22 & $(.88)$ & & \\
\hline 7. Recom intent (T1) & 3.66 & .95 & -.03 & $.29 *$ & .02 & .14 & $.55^{* *}$ & .08 & $(-)$ & \\
\hline 8. Recom intent (T2) & 3.45 & 1.10 & .14 & $.38 * *$ & $.37 * *$ & .10 & -.07 & $.67 * *$ & .22 & $(-)$ \\
\hline
\end{tabular}

Notes: Reliability coefficients per measurement appear on the diagonal. Selection outcome: reject $=0$; pass $=1$.

$*_{p}<.05, * * p<.01, * * * p<.001$ (two-tailed).

Table 7. Regression of organizational attractiveness and recommendation intentions on procedural fairness, distributive fairness and attributional style, Study 3

\begin{tabular}{|c|c|c|c|c|c|c|}
\hline Dependent variable & $B$ & $\beta$ & $R 2$ & $\Delta R 2$ & $F$ & $\Delta F$ \\
\hline \multicolumn{7}{|l|}{$\begin{array}{l}\text { Organizational } \\
\text { attractiveness }\end{array}$} \\
\hline Step 1 & & & .05 & - & 2.90 & - \\
\hline Org attractiveness T1 & .13 & .10 & & & & \\
\hline Step 2 & & & .32 & .27 & 6.22 & $7.02 * * *$ \\
\hline Procedural fairness & .61 & $.52 * * *$ & & & & \\
\hline Distributive fairness & -.02 & -.02 & & & & \\
\hline Attributional style & -.10 & -.10 & & & & \\
\hline Step 3 & & & .48 & .16 & 7.89 & $8.01 * * *$ \\
\hline $\mathrm{PF} \times$ Attrib style & .04 & .03 & & & & \\
\hline DF $\times$ Attrib style & -.29 & $-.42 * * *$ & & & & \\
\hline \multicolumn{7}{|l|}{$\begin{array}{l}\text { Recommendation } \\
\text { intention }\end{array}$} \\
\hline Step 1 & & & .05 & - & 2.77 & - \\
\hline Recommend intent T1 & .19 & .18 & & & & \\
\hline Step 2 & & & .18 & .13 & 2.90 & $2.86 *$ \\
\hline Procedural fairness & .46 & $.30 *$ & & & & \\
\hline Distributive fairness & .11 & .12 & & & & \\
\hline Attributional style & .02 & .01 & & & & \\
\hline Step 3 & & & .24 & .06 & 2.74 & $2.15^{*}$ \\
\hline PF $\times$ Attrib style & -.00 & -.00 & & & & \\
\hline DF $\times$ Attrib style & -.25 & $-.27^{*}$ & & & & \\
\hline
\end{tabular}

Notes: The reported statistics are standardized regression coefficients and are for the final equation, including all independent variables. Org attract: df Step $1=(1,57)$; df Step $2=(4,54)$; df Step $3=(6$, $52)$; total $d f$ all steps $=58$; Recommend intent: $d f$ Step $1=(1,56)$; $d f$ Step $2=(4,53)$; df Step $3=(6,51)$; total $d f$ all steps $=57$

$* p<.05$, *** $p<.001$ (two-tailed).

study variables; therefore they were not included in the further analyses. Means and standard deviations of $\mathrm{T} 1$ and T2 organizational attractiveness and recommendation intention for hired and rejected applicants are shown in Table 1. Table 6 shows correlations between the variables.

Similar regression analyses were performed as in the previous studies. For Hypothesis $1 a$ and $1 b$, results revealed that procedural fairness was indeed positively related to organization attractiveness $(F(4,54)=6.22$, $p<.001)$ and recommendation intention $(F(4,53)=2.90$, $p<.05$ ), but distributive fairness was not (see Table 7). That is, applicants who perceived the procedure as more fair thought the organization was more attractive and

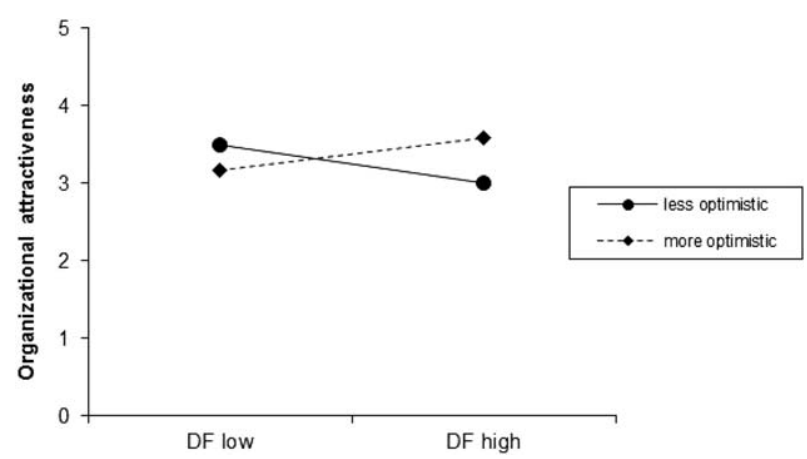

Figure 2. Organizational attractiveness across distributive fairness (DF: low vs. high) and attributional style (less vs. more optimistic), Study 3. (Figure based on $+/-1 S D$ of independent variables).

were more willing to recommend it to others than those who perceived it as unfair. This means that, in this study, Hypothesis $1 b$ was supported, but Hypothesis $1 a$ was not.

For Hypothesis 2a, regression results revealed that the fairness-attractiveness relationship was indeed moderated by attributional style: $F(6,52)=7.89, p<.001$, for the final equation (Table 7). Slopes analyses (Dawson, 2014) revealed that this effect was significant at both a low (-1 SD: $t=-4.22, p<.001)$ and a high level $(+1 S D$ : $t=1.94, p<.05)$ of optimistic attribution style. The power of this step is $f^{2}=.31$, which is considered large. Figure 2 shows that the pattern was similar to that in Study 2: applicants with a more optimistic attribution style reported higher organizational perceptions than less optimistic individuals when they perceived the outcome as fair, but lower perceptions when they perceived the outcome as unfair. It should be noted that, in the present study - contrary to our hypothesis - less optimistic applicants also reacted to (un)fairness, but in the opposite direction: Hypothesis $2 a$ was partially supported.

For recommendation intentions (Hypothesis $2 b$ ), no significant moderation effect was found: $F(6,51)=2.74$, $p=n s$, for the final equation (Table 7). Despite the nonsignificance of the variance explained by the additional step, the beta for the moderation effect was significant: $\beta=-.27, p<.05$, rendering the pattern for recommendation intention informative. Simple slopes analyses revealed that this effect was only moderately significant at 
a high level (+1 SD) of optimistic attribution style $(t=1.38, p<.10)$, thus, optimistic applicants reporting stronger reactions to (un)fairness than less optimistic ones. The power of this step is relatively small: $f^{2}=.08$. This means that, in Study 3. Hypothesis $2 b$ was not supported.

\section{Study 4}

The goal of Study 4 was to examine whether the finding from the previous field studies, that the relationship between distributive fairness and attractiveness and intentions was moderated by attributional style, would also occur in a controlled context.

\subsection{Method}

\subsubsection{Participants and procedure}

Participants $(N=213)$ were undergraduate students at a Dutch university who received either course credit or a monetary reward for participating. The sample mainly consisted of Psychology students (78\%) and women (76\%); participants' mean age was $21(S D=4)$.

The study entailed a $2 \times 2$ between-subjects design, with 'selection outcome' (positive vs. negative) and 'test score provision (yes vs. no)' as experimental manipulation. Upon entering the laboratory, participants were placed at a personal computer station and were given an informed consent form. Confidentiality of answers was guaranteed. After filling out the attributional style questionnaire, they were asked to imagine being an applicant, and read the job vacancy on the computer screen. Then, they were given two GMA-tests, and were told only the top-20\% performers on the GMA-tests (based on alleged norm) would be invited to a subsequent selection interview (on average, companies hire about one out of five applicants that are invited to a first selection round). The tests (Guilford, 1971) were chosen because they are as little language- and knowledge-related as possible and resembled tests that are typically used in assessment settings (Horvath, Ryan, \& Stierwalt, 2000). Upon test completion, the computer provided all participants with a selection outcome (including/excluding alleged test score). Next, participants were given the DVquestionnaires, followed by the procedural and distributive fairness questionnaires. Finally, they were extensively debriefed by the computer, informing them that the outcome did not reflect their true test performance and was only given for research purposes.

\subsubsection{Measures}

Measures were the same as in Study 3, with two exceptions. Procedural fairness perceptions in this study were measured with six items (job-relatedness, opportunity to perform). Organizational attractiveness was measured with two items (see Table 8 for reliabilities).

\subsection{Results}

None of the demographic variables (gender, age, nationality) related to the study variables; thus were not included in analyses (see Table 8 for correlations). Similar regression analyses as for the three previous studies were performed. Because, in this study, selection outcome was related to organization attractiveness and intentions, we ran analyses both excluding (to preserve power) and including this variable.

For Hypotheses $1 a$ and $1 b$, results revealed that both distributive and procedural fairness were strongly positively related to organization attractiveness $(F(3$, $209)=12.25, p<.001)$ and recommendation intentions $(F(3,167)=7.58, p<.001)$ (see Table 9). That is, higher procedural and distributive fairness resulted in higher organization attractiveness as well as in stronger recommendation intentions. This means that both Hypothesis $1 a$ and $1 b$ were supported.

For Hypothesis 2, it was found that the relationship between distributive fairness on the one hand and a) organization attractiveness and b) recommendation intention $(\mathrm{H} 2 \mathrm{~b})$ on the other was not moderated by attributional style: $F(5,207)=7.50, p=n s ; F(5,165)=4.74, p=n s$, respectively, for the final equation (Table 9). (Note that, when outcome is also controlled for, these effects remain nonsignificant.) Additional moderated regression analyses, however, revealed that, for recommendation intention, a significant moderation effect did occur in the 'pass' condition: $F(5,79)=6.15, p<.01$, for the final equation

Table 8. Means, standard deviations, reliabilities and correlations of Study 4 variables

\begin{tabular}{|c|c|c|c|c|c|c|c|c|}
\hline Measures & $M$ & $S D$ & 1 & 2 & 3 & 4 & 5 & 6 \\
\hline 1. Selection outcome & - & - & $(-)$ & & & & & \\
\hline 2. Proced fairness & 2.06 & .65 & .11 & $(.78)$ & & & & \\
\hline 3. Distrib fairness & 2.58 & 1.06 & $.14 *$ & $.27^{* * *}$ & $(-)$ & & & \\
\hline 4. Attribution style & 2.70 & .89 & -.02 & .00 & .06 & $(.84)$ & & \\
\hline 5. Org attract (T2) & 2.83 & .87 & $.17^{*}$ & $.29 * * *$ & $.30 * * *$ & -.10 & $(-)$ & \\
\hline 6. Recom intent (T2) & 2.94 & 1.26 & $.17^{*}$ & $.31 * * *$ & $.23 * *$ & -.04 & $.52 * * *$ & $(-)$ \\
\hline
\end{tabular}

Notes: Reliability coefficients per measurement appear on the diagonal. Selection outcome: reject $=0$; pass $=1$. Organizational attractiveness: $r=.49$.

$*_{p}<.05, * * p<.01, * * * p<.001$ (two-tailed). 
Table 9. Regression of organizational attractiveness and recommendation intentions on procedural fairness, distributive fairness and attributional style, Study 4, all subjects

\begin{tabular}{|c|c|c|c|c|c|c|}
\hline Dependent variable & B & $\beta$ & $R 2$ & $\Delta R 2$ & $F$ & $\Delta F$ \\
\hline \multicolumn{7}{|l|}{ Organizational attractiveness } \\
\hline Step 1 & & & .15 & - & $12.25 * * * *$ & - \\
\hline Procedural fairness & .29 & $.22 * * * *$ & & & & \\
\hline Distributive fairness & .20 & $.25 * * * *$ & & & & \\
\hline Attributional style & -.11 & $-.12^{*}$ & & & & \\
\hline Step 2 & & & .15 & .01 & 7.50 & .47 \\
\hline $\mathrm{PF} \times$ Attrib style & -.08 & -.10 & & & & \\
\hline DF $\times$ Attrib style & -.05 & -.06 & & & & \\
\hline \multicolumn{7}{|l|}{ Recommendation intention } \\
\hline Step 1 & & & .12 & - & $7.58 * * * *$ & - \\
\hline Procedural fairness & .50 & $.26 * * * *$ & & & & \\
\hline Distributive fairness & .19 & $.15^{* *}$ & & & & \\
\hline Attributional style & -.07 & -.05 & & & & \\
\hline Step 2 & & & .13 & .01 & 4.74 & .58 \\
\hline PF $\times$ Attrib style & -.08 & -.05 & & & & \\
\hline DF $\times$ Attrib style & -.11 & -.09 & & & & \\
\hline
\end{tabular}

Note: The reported statistics are standardized regression coefficients and are for the final equation, including all independent variables. Org attract: df Step $1=(3,209)$; df Step $2=(5,207)$; total $d f$ all steps $=212$; Recommend intent: $d f$ Step $1=(3,167)$; df Step $2=(5,165)$; total df all steps $=170$.

$* p<.10 ; * * p<.05, * * * * p<.001$ (two-tailed).

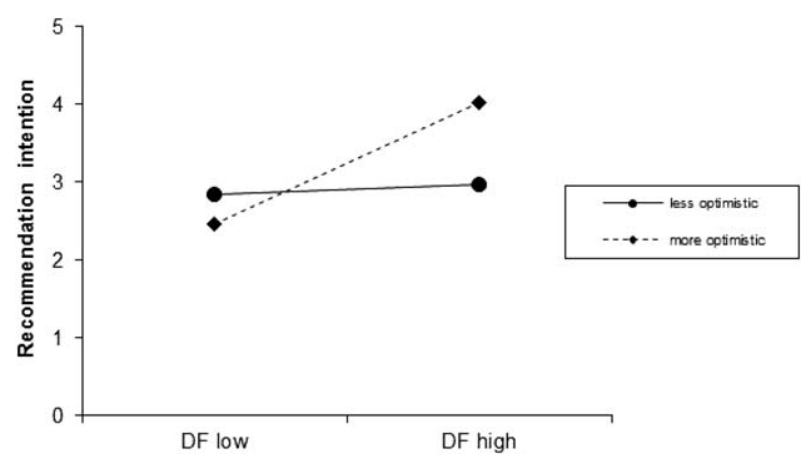

Figure 3. Recommendation intention of 'passed' individuals across distributive fairness (DF: low vs. high) and attributional style (less vs. more optimistic), Study 4. (Figure based on $+/-1$ SD of independent variables).

(Table 10). Simple slopes analyses showed this effect was significant at a high level $(+1 S D: t=3.24, p<.01)$ but not at a low level $(-1$ SD: $t=1.95, p=n s)$ of optimistic attribution style. The power of this step is medium: $f^{2}=.13$ (Cohen, 1988). That is, for individuals who had allegedly passed the GMA-tests, attributional style did moderate the fairness-intention relationship, with more optimistic applicants reporting higher intentions to recommend the organization to others than less optimistic individuals, when the outcome was perceived as fair (see Figure 3). Thus, in Study 4, Hypothesis $2 a$ was not supported and Hypothesis $2 b$ was only partially supported.

\section{General discussion}

The results of the four studies presented in this paper supported our hypotheses to a certain extent. As expected, a direct positive relationship between proced- ural fairness and perceptions and intentions was found in all studies concerned (Studies 1, 3, and 4; not measured in Study 2). That is, regardless of the selection outcome, applicants perceived the organization as more attractive and were more inclined to recommend it to others when they regarded the selection procedure (Studies 1 and 3: interview, Study 4: GMA-test) as fair. This finding is in line with previous research showing higher attraction to the organization and recommendation intentions when selection procedures are perceived as fair (see also: Hausknecht et al., 2004). Further, a direct (positive) relationship between distributive fairness and perceptions and intentions was found in Studies 2, and 4, but not in Studies 1 and 3. This reflects the discrepancy in existing research, where a (positive) relationship is found in some, but not in other studies (see also: Hausknecht et al., 2004). Note that in three studies of this paper, a positive correlation was found between perceived distributive fairness on the one hand and attractiveness and intentions on the other. However, in two of the three studies that also included procedural fairness, distributive fairness did not relate to attraction and intention if procedural fairness was controlled for in the regression equation (correlations between procedural and distributive fairness range between .27 and .42 ).

Further, the primary focus of this study, an overall moderation of the distributive fairness-organizational attractiveness relationship by attributional style, was found in both authentic context studies in which it was examined (Studies 2 and 3). In the hypothetical context study (Study 4), however, no such effect was found. For recommendation intentions, results indicated moderation in one of the field studies (Study 2), but only when analyses were performed excluding T1 (greatly increasing sample size). 
Table 10. Regression of organizational attractiveness and recommendation intentions on procedural fairness, distributive fairness and attributional style, Study 4 , selected participants

\begin{tabular}{|c|c|c|c|c|c|c|}
\hline Dependent variable & $B$ & $\beta$ & $R 2$ & $\Delta R 2$ & $F$ & $\Delta F$ \\
\hline \multicolumn{7}{|l|}{ Organizational attractiveness } \\
\hline Step 1 & & & .14 & - & $5.78 * * * *$ & - \\
\hline Procedural fairness & .15 & .12 & & & & \\
\hline Distributive fairness & .26 & $.32 * * * *$ & & & & \\
\hline Attributional style & -.13 & -.13 & & & & \\
\hline Step 2 & & & .15 & .01 & 3.68 & .60 \\
\hline PF $\times$ Attrib style & -.08 & -.08 & & & & \\
\hline DF $\times$ Attrib style & -.09 & -.11 & & & & \\
\hline \multicolumn{7}{|l|}{ Recommendation intention } \\
\hline Step 1 & & & .19 & - & $6.44 * * * *$ & - \\
\hline Procedural fairness & .18 & .10 & & & & \\
\hline Distributive fairness & .40 & $.36 * * * *$ & & & & \\
\hline Attributional style & -.18 & -.14 & & & & \\
\hline Step 2 & & & .28 & .09 & 6.15 & $4.80 * * * *$ \\
\hline PF $\times$ Attrib style & -.17 & -.13 & & & & \\
\hline DF $\times$ Attrib style & -.37 & $-.35 * * *$ & & & & \\
\hline
\end{tabular}

Notes: The reported statistics are standardized regression coefficients and are for the final equation, including all independent variables. Org attract: $d f$ Step $1=(3,103)$; $d f$ Step $2=(5,101)$; total $d f$ all steps $=106$; Recommend intent: $d f$ Step $1=(3,81) ; d f$ Step $2=(5,79)$; total $d f$ all steps $=84$.

$* * * p<.01, * * * * p<.001$ (two-tailed).

In the laboratory environment a similar effect was found, but merely for individuals who had allegedly passed the selection test. It should be noted that the lack of moderation effects for recommendation intention may also be due to the fact that this dependent variable was measured with only one item.

In line with our expectations, individuals with a more optimistic attributional style generally reacted more strongly to (un)fairness than less optimistically attributing individuals. However, in some cases (Study 3), less optimistic individuals also showed strong reactions to (un)fairness, but in the opposite direction. That is, the pattern of results was quite similar over the studies: overall, when the outcome was perceived as fair, optimistically attributing individuals reported more positive perceptions of the recruiting organization than less optimistic individuals. In contrast, optimistic individuals reported lower organization perceptions than less optimistic ones if they perceived the selection outcome they had received as unfair.

\subsection{Strengths, limitations and implications}

The studies in this paper have a number of strengths: use of actual applicants, multiple studies, pretest and postoutcome measurement, and combining procedural and distributive justice. However, several potential limitations should be noted. First, method bias may have occurred: outcomes (organization attractiveness and recommendation intentions) were measured simultaneously with fairness perceptions (i.e., after participants were provided with the selection outcome). However, perceived distributive fairness can only be assessed after applicants have received their selection outcome (Bauer et al., 1998). Further, because in Studies 2 and 4 outcome was related to T2-reactions, we reran analyses for these studies, controlling for outcome. It was found that the regression results did not change (see Studies 2 and 4 results for details). Nevertheless, future research should measure relevant reactions both shortly before and after the outcome is provided. Also, in the three field studies, applicant experiences before T1-measurement may have differed in the field studies, as controlling for contextual factors is not possible in this type of research. However, the fourth study in our paper was conducted in an experimental context, thus allowing (at least to some extent) more control over applicant experiences than the three field studies.

Note that much of the research on perceptions of selection processes has focused on fairness perceptions assessed immediately after the process but before the outcome. However, designs that only consider preoutcome applicant perceptions have been criticized as painting an inaccurate picture (Ployhart \& Harold, 2004; Ryan \& Ployhart, 2000). Additionally, even fewer studies have controlled for pretest levels of perceptions. Second, distributive fairness was measured with only one and two items (with relatively modest correlations: .69 and .59) and recommendation intention was measured with only one item; however, findings were consistent and generally in line with hypothesized effects. Third, in Studies 1 and 3, far less applicants were hired than rejected. However, a low selection ratio replicates most real-life selection situations. Fourth, we did not investigate possible differential effects of the fairness subscales, as power was not strong enough for the separate analyses. Future research should investigate whether the different fairness (SPJS) subscales have differential relationships with applicant reactions. Also, because in Study 3 applicants applied to a wide variety of organizations, the extent to which interviews were 
structured varied. We did not measure interview structure in our studies; therefore, we suggest future research investigate this issue. Finally, although performance and outcome may be highly related, we did not have information on applicants' interview performance (Studies 1 and 3 ) and were, thus, unable to examine if this may have affected our findings. Future research is needed to investigate these matters.

This paper provides several implications for future research and practice. First, our findings indicate that studies in a hypothetical context should not replace investigations of applicant reactions in authentic contexts. In contrast to the finding by Hausknecht et al. (2004), direct relationships between fairness and organizational outcomes generally were less strong in our hypothetical context study than in our actual selection context studies. Furthermore, moderation effects were only found in the field studies, not in the experimental study. To increase the ecological validity of personnel selection research, more research in actual, high-stakes selection situations with real applicants is warranted.

Further, the finding that attributional processing moderates the relationship between distributive fairness and applicants' perceptions of and intentions toward the hiring organization advances our insight into the formation of applicant reactions. It may explain, for instance, the inconsistency in the existing literature, in which some studies found direct effects of distributive fairness (e.g., Gilliland, 1994; Ployhart \& Ryan, 1997; 1998; Schinkel, et al., 2011), whereas several others did not (Schinkel, et al., 2013; Smither et al., 1993). Our findings may further indicate individual differences in the occurrence of a self-serving bias (Miller \& Ross, 1975): people are generally less inclined to take responsibility for negative than for positive events, but differences in inclination may exist. Thus, particularly individuals with a more optimistic style may be prone to self-serving biases, and consequently may blame some external factor (e.g., unattractive organization, biased selection committee) for the cause of their negative experience (Ployhart \& Ryan, 1997). This may be beneficial to applicants, for instance to maintain a positive self-image after being rejected; however, it can simultaneously result in negative reactions toward the organization. Despite several calls for research (e.g., Chan \& Schmitt, 2004; Ployhart \& Harold, 2004; Ryan \& Ployhart, 2000), to date, little attention has been given to the psychological processes through which this bias can develop and what consequences it may have. Investigations of personal (selfesteem, motivation, behavior) and organizational reactions should not be performed in isolation, but simultaneously, in order to get more insight into the possible contradictions in these two types of outcomes.

While organizations may not be inclined to assess applicants' attributional styles, counselors may do so to improve job seekers' self-image and subsequent career success. That is, coaching job seekers about how their attributional style affects their reactions to rejections and experiences of unfairness in job search can help them maintain positive self-efficacy and outlook.

Further, the findings here indicate that both procedural and distributive justice perceptions are important to attend to in selection contexts. Organizations may not fully appreciate how to enhance distributive justice, given that they will be rejecting a number of applicants. However, steps such as clarifying what 'inputs' (experience, KSAs, educational background) are required to be selected can help applicants better assess their own inputs. Providing this general guidance regarding what constitutes a qualified applicant can lead individuals to use a more appropriate referent in making the social comparisons that can underlie distributive justice judgments. Finally, attending to procedural justice through providing more information about the selection procedure, increasing two-way communication, explaining the job relevance of criteria, and the like are also ways for organizations to enhance fairness perceptions.

Finally, because word-of-mouth may be a very powerful source for organizational attractiveness (Van Hoye \& Lievens, 2005), preserving applicants' positive perceptions of the recruiting organization is very important (Hausknecht et al., 2004). In general, organizations must recognize that applicants differ in ways that can affect how they react to the hiring process - in attributional style as well as other attributes - and thus increasing positive perceptions of attractiveness and intentions to recommend even when experiencing an unfavorable selection outcome may require greater investments.

\section{References}

Ababneh, K. I., Hackett, R. D., \& Schat, A. C. H. (2014). The role of attributions and fairness in understanding job applicant reactions to selection procedures and decisions. Journal of Business Psychology, 29, 111-129.

Abu Ghazaleh, N., Den Hartog, D. N., \& Schinkel, S. (2008). Antecedents of ethnic minority applicants' perceptions of selection discrimination. Paper presented at Institute of Work Psychology (IWP) Conference, June 2008, Sheffield, UK.

Abramson, L. Y., Seligman, M. E. P., \& Teasdale, J. D. (1978). Learned helplessness in humans: Critique and reformulation. Journal of Abnormal Psychology, 87, 49-74.

Anderson, N. (2011). Perceived Job Discrimination: Toward a model of applicant propensity to case initiation to selection. International Journal of Selection and Assessment, 19, 229-244.

Bauer, T. N., Maertz, C. P., Dolen, M. R., \& Campion, M. A. (1998). Longitudinal assessment of applicant reactions to employment testing and test outcome feedback. Journal of Applied Psychology, 83, 892-903.

Bauer, T. N., Truxillo, D. M., Sanchez, R. J., Craig, J., Ferrara, P., \& Campion, M. A. (2001). Applicant reactions to selection: Development of the Selection Procedural Justice Scale (SPJS). Personnel Psychology, 54, 387-419. 
Becker, T. E. (2005). Potential problems in the statistical control of variables in organizational research: A qualitative analysis with recommendations. Organizational Research Methods, 8, 274-289.

Chan, D., \& Schmitt, N. (2004). An agenda for future research on applicant reactions to selection procedures: A constructoriented approach. International Journal of Selection and Assessment, 12, 9-23.

Cheng, H., \& Furnham, A. (2003). Attributional style and selfesteem as predictors of psychological well being. Counselling Psychology Quarterly, 16, 121-130.

Cohen, J. (1988). Statistical power for the social sciences. Hillsdale, NJ: Lawrence Erlbaum and Associates.

Dawson, J. F. (2014). Moderation in management research: What, why, when, and how. Journal of Business Psychology, 29, 1-19.

Derous, E., Born, M. Ph., \& De Witte, K. (2004). How applicants want and expect to be treated: Applicants' selection treatment beliefs and the development of the Social Process Questionnaire of Selection. International Journal of Selection and Assessment, 12, 99-119.

Forsterling, F. (2001). Attribution: An introduction to theories, research and applications. New York: Psychology Press.

Gilliland, S. W. (1993). The perceived fairness of selection systems: An organizational fairness perspective. Academy of Management Review, 18, 694-734.

Gilliland, S. W. (1994). Effects of procedural and distributive fairness on reactions to a selection system. Journal of Applied Psychology, 79, 117-127.

Guilford, J. P. (1971). The analysis of intelligence. New York: McGraw-Hill.

Hausknecht, J. P., Day, D. V, \& Thomas, S. C. (2004). Applicant reactions to selection procedures: An updated model and meta-analysis. Personnel Psychology, 57, 639-683.

Horvath, M., Ryan, A.M., \& Stierwalt, S.L. (2000). The influence of explanations for selection test use, outcome favorability, and self-efficacy on test-taker perceptions. Organizational Behavior and Human Decision Processes, 83, 310-330.

Miller, D. T., \& Ross, M. (1975). Self-serving biases in the attribution of causality: Fact or fiction? Psychological Bulletin, 82, 213225.

Peterson, C., \& Villanova, P. (1988). An expanded attributional style questionnaire. Journal of Abnormal Psychology, 97, 87-89.

Ployhart, R. E., \& Harold, C. M. (2004). The Applicant Attribution-Reaction Theory (AART): An integrative theory of applicant attributional processing. International Journal of Selection and Assessment, 12, 84-98.

Ployhart, R. E., \& Ryan, A. M. (1997). Toward an explanation of applicant reactions: An examination of organizational fairness and attribution frameworks. Organizational Behavior and Human Decision Processes, 72, 308-335.

Ployhart, R. E., \& Ryan, A. M. (1998). Applicants' reactions to the fairness of selection procedures: The effects of positive rule violation and time of measurement. Journal of Applied Psychology, 83, 3-16.

Proudfoot, J. G., Corr, P. J., Guest, D. E., \& Gray, J. A. (2001). The development and evaluation of a scale to measure occupational attributional style in the financial services sector. Personality and Individual Differences, 30, 259-270.

Ryan, A. M., \& Ployhart, R. E. (2000). Applicants' perceptions of selection procedures and decisions: A critical review and agenda for the future. Journal of Management, 26, 565-606.

Scheier, M. F., \& Carver, C. S. (1993). On the power of positive thinking: The benefits of being optimistic. Current Directions in Psychological Science, 2, 26-30.

Schinkel, S., Van Dierendonck, D., Van Vianen, A. E. M., \& Ryan, A. M. (2011). Applicant reactions to rejection: Feedback, fairness and attributional style effects. Journal of Personnel Psychology, 10,146-156.

Schinkel, S., Van Vianen, A. E. M., \& Van Dierendonck, D. (2013). Selection fairness and outcomes: A field study of interactive effects on applicant reactions. International Journal of Selection and Assessment, 21, 22-31.

Smither, J. W., Reilly, R. R., Millsap, R. E., Pearlman, K., \& Stoffey, R. W. (1993). Applicant reactions to selection procedures. Personnel Psychology, 46, 49-76.

Stevens, M. (2010). Poor treatment of failed job applicants 'hurts consumer brand'. People Management Online. Available at http://www.peoplemanagement.co.uk/pm/articles/2010/06/ poor-treatment-of-failed-job-applicants-hurts-consumerbrand.htm (accessed June 8, 2010).

Truxillo, D. M., Bauer, T. N., Campion, M. A., \& Paronto, M. E. (2002). Selection fairness information and applicant reactions: A longitudinal field study. Journal of Applied Psychology, 87, 1020-1031.

Uggerslev, K. L., Fassina, N. E., \& Kraichy, D. (2012). Recruiting through the stages: A meta-analytic test of predictors of applicant attraction at different stages of the recruiting process. Personnel Psychology, 65, 597-660.

Van Hoye, G. \& Lievens, F. (2005). Recruitment-related Information sources and organizational attractiveness: Can something be done about negative publicity? International Journal of Selection and Assessment, 13, 179-187.

Wagner, K. D., Berenson, A., Harding, O., \& Joiner, T. (1998). Attributional style and depression in pregnant teenagers. The American Journal of Psychiatry, 155, 1227-1233.

Weiner, B. (1986). An attributional theory of motivation and emotion. New York: Springer Verlag. 